
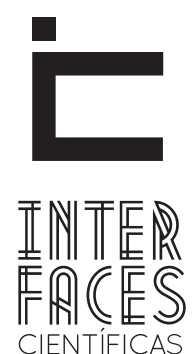

EDUCAÇÃO

ISSN IMPRESSO 2316-333X

ISSN ELETRÔNICO 2316-3828

\title{
GIBI QUILOMBOS: \\ POR DENTRO DOS MUROS DAS ESCOLAS BRASILEIRAS
}

Ana Fátima Cruz dos Santos ${ }^{1}$

\section{RESUMO}

A educação quilombola no Brasil tem obtido avanços em conquistas legislativas e amplitude de sua dinâmica coletiva enquanto exemplo de tradição afro-brasileira além de conquistarem outras demandas como registro da terra, manutenção da cultura e costumes e uma educação que respeite a organização da sociedade local. No século XXI, a formação de um currículo que alcance objetivos básicos dos quilombolas provocou diversos debates e até mesmo a construção de uma cartilha que orientasse a elaboração de diretrizes educativas específicas para estes povos afro-brasileiros. Objetiva-se apresentar neste trabalho o quadro de produção de materiais impressos em quadrinhos para as escolas de comunidades quilombolas ou outras instituições escolares que planejam abordar o tema em sua sala de aula. Após a implementação da Resolução $n^{0} 8$ das Diretrizes Curriculares Nacionais para a educação quilombola na educação básica, 2012, questiona-se: Há uma produção significativa e incentivadora por parte das representações municipais, estaduais e federais de Educação para estas instituições educativas? Serão expostos alguns revistas de contação de histórias em quadrinhos relacionadas ao ensino escolar tanto em quilombos urbanos quanto em quilombos rurais (do campo) indicados para uso escolar. A análise terá como critérios o uso adequado de terminologia correspondente ao conceito de quilombo e suas vivências, adequação de imagens representativas e compatibilidade com o contexto em que o material é inserido. A pesquisa terá a Crítica Cultural e a Linguística Aplicada enquanto suportes teórico-metodológicos para a investigação destes materiais e os conceitos que os mesmos carregam em seu conteúdo.

\section{PALAVRAS-CHAVE}

Letramentos. Educação Quilombola. Quadrinhos. Linguagem, Interdisciplinaridade. 


\section{ABSTRACT}

The maroon education in Brazil has achieved legislative advances and extends their collective dynamics as an example of Afro-Brazilian tradition of winning besides other demands such as land registration, maintenance of culture and customs, and an education that respects the organization of local society. In the XXI century, the formation of a curriculum that achieves basic objectives of the maroons caused many debates and even the construction of a primer to orient the development of specific educational guidelines for these Afro-Brazilian people. This work aims to present the production of printed comics for maroon communities' school or other educational institutions which plan to address the subject in their classroom. After the implementation of Resolution No. 8 of the National Curriculum Guidelines for maroons' basic education, 2012, the question is: Is there a significant production and incentive from the municipality, state and federal representation of education for these educational institutions? Some storytelling comic magazines related to school education in both urban and rural Quilombo (field) suitable for school use will be exposed. The criterion for the analysis is check if the concept of the maroons and their experiences are according to the related terminology, as well as, the representative images and the compatibility with the context that the material is inserted. The research will use Cultural Review and Applied Linguistics as the theoretical and methodological supports for the investigation of these materials and concepts that they carry on their content.

\section{KEYWORDS}

Literacies. Maroon Education. Comics. Language. Interdisciplinarity.

\section{RESUMEN}

La educación quilombola, o marrón, en Brasil ha logrado avances en los logros legislativos y la amplitud de sus dinámicas colectivas como un ejemplo de la tradición afrobrasileña de ganar, además de otras demandas tales como el registro de tierras, el mantenimiento de la cultura y las costumbres, y una educación que respete la organización de la sociedad local. Para mejor comprensión, se esclarece que quilombo significa decir antiguos refugios de esclavos en el medio rural en tiempos antiguos de la esclavitud en Brasil. En el siglo XXI , la formación de un plan de estudios que alcanza los objetivos básicos de los cimarrones causado muchos debates e incluso la construcción de un manual para orientar el desarrollo de pautas educativas específicas para estas personas afro- brasileña. Tiene como objetivo presentar este trabajo en la producción de cajas de materiales impresos en los cómics a las escuelas comunidades cimarronas u otras instituciones educativas que tengan previsto abordar la cuestión en las clases. Después de la aplicación de la Resolución $N^{\circ} 8$ de las Directrices Curriculares Nacionales para la educación en marrón educación básica 2012 , la pregunta es : ¿Hay una producción y un incentivo significativo por parte de los locales, estatales y federales oficinas de educación para estas instituciones educativas ? Algunas revistas de narración de cuentos en los cómics relacionados con la educación escolar, tanto en el medio urbano como en el rural Quilombo (campo) adecuado para uso de la escuela va a estar expuesto. El análisis tendrá como criterios de uso apropiado correspondientes al concepto de marrón y sus experiencias, la adecuación de imágenes representativas y la compatibilidad con el contexto en el que se introduce el material de la terminología. La investigación tendrá la Crítica Cultural y Lingüística Aplicada a los soportes teóricos y metodológicos para la investigación de estos materiales y conceptos enriquezcan su contenido.

\section{PALABRAS CLAVE}

Alfabetización. Educación Marrón. Los Cómics. El Idioma. La Interdisciplinariedad. 


\section{INTRODUÇ̃̃̃O}

Realizar leituras sobre os diversos agentes de letramento tem sido uma prática recorrente para pesquisadores interessados em discutir e aproximar uma educação para a diversidade, Indisciplinar (MOITA LOPES, 2006) e plural. Apresente-se as perspectivas de letramento segundo Kleiman (2005) e Ana Lucia Souza (2011), a relevância de se problematizar a educação como ensino global e pós-colonial (MIGNOLO, 2008). É do lugar de pesquisadores, críticos culturais e educadores que busca-se uma sociedade que entenda as diferenças (raciais, de classe e gênero) e as respeite rumo a relações saudáveis e possíveis de mudança.

É preciso compreender a importância da pesquisa, em qualquer tipo de área do conhecimento, como um modo de construir a vida social, dar sentido a mesma levando em conta a pluralidade do conhecimento. É sobre isto que a epígrafe no início deste texto quer apontar: um olhar atento a determinadas instituições ideológicas, políticas e sociais que existem no Brasil e o torna um Estado plural e sinônimo de resistência negra. Ao passo que se observa as relações interpessoais, nota-se, também, que as identidades têm atingido um estágio fluido. Estas identidades são globais e locais ao mesmo tempo; dão sentindo a um mundo multifacetado e com referencia ao simbólico assim como ao cultural.

A globalização está diretamente envolvida no processo educacional uma vez que define os meios comunicacionais usados pelos usuários da linguagem (oral e escrita) assim como os conceitos cambiantes nas leituras sobre linguagem, cultura e sociedade pós-moderna. Contudo, a globalização tem se tornado ainda mais descentralizada (GIDDENS, 2000 apud MIOTA LOPES, 2006), envolvendo diversas culturais e a imbricação de umas com as outras. Ou seja, a homogeneização cultural tenciona com a ideia de heteroge- neizacao cultural, transformando o sentido de cultura derivante para o sentido de manifestações culturais autônomas, que ressignificam a tradição e enfrentam os padrões coloniais. Conforme Moita Lopes:

Azelene Kaingáng baseou seu argumento em seu posicionamento como indígena, mostrando que historicamente os indígenas brasileiros têm lutado pela manutenção das fronteiras nacionais. São esses discursos que entendo como questionadores da lógica ocidentalista (MOITA LOPES, 2006, p.88)

A transformação dos ideais coloniais para pós-coloniais favoreceram a transformação do moderno para o pós-moderno buscando interagir formas alternativas de expressão e interpretação, desafiando hegemonias e provocando desconstruções. Em meio a estas desconstruções está a linguagem (pós-moderna) que deixa de ser concebida enquanto um sistema para ser discurso - designa o território conceitual inteiro no qual o conhecimento é produzido e reproduzido. Assim como nos diz Foucault em Microfísica do Poder: a linguagem enquanto organismo do discurso.

Estes discursos possuem uma carga simbólica que favorece a construção de enunciados que transformam a visão de mundo, transgride a colonização epistêmica e edifica uma identidade em política (MIGNOLO, 2008). Mas o que vem a ser esta identidade em política? Vem a ser um pensamento de fronteira ou epistemologia de fronteira que desafia os essencialistas da linguagem e inclui nesta a geopolítica do conhecimento. Por sua vez, a geopolítica do conhecimento alia-se ao conceito de interculturalidade, exemplificando-o, as comunidades quilombolas que sempre exerceram sua geopolítica em um uso de suas técnicas e artes. Como nos diz Clóvis Moura, o quilombo é uma reelaboração de comunidades livres (MOURA, 1993). 


\section{LETRAMENTO EU, LETRAMENTO NÓS}

Visto que, em dada cultura, não há apenas um letramento, mas letramentos múltiplo associados aos vários domínios da vida, bem como diversidade nos modos como os sujeitos tomam parte em eventos e situações nesses domínios (...)

Ana Lúcia Silva Souza

Pensar sobre o letramento para além de aprender a ler e escrever, para além da alfabetização nos permite desenvolver as habilidades para o aprendizado com a vivência, a interação com demais indivíduos no mundo, aprender com outras culturas (SOUZA, 2011). Baseada nos campos teóricos Bakhtinianos, dos estudos Culturais e da Linguística Aplicada (por Kleiman, 1995). Ana Lúcia Souza conduz a que se observem as marcas da cultura hip-hop que valorizam uma educação plural e as relações de identidade e poder que esta cultura veicula em seu discurso, favorecendo a elevação da autoestima da população negra e os fazendo compreender sobre política, relações sociais e economia por meio da música, dança e letra politizada.

Assim como Souza (2011), rejeita-se a ideia de letramento fixada pelos europeus. A autora em sua obra Letramentos de Reexistência (2011) traz ao centro das “narrativas sobre escolarização no Brasil”, táticas e estratégias pouco conhecidas nacionalmente e tão praticadas pela população negra, "em confronto com uma estrutura política, econômica e cultural historicamente desfavorável” (SOUZA, p. 38). E a musicalidade é um elemento (uma agente de letramento) de sustentação da organização social, cultural e política do hip-hop.

Para que se encha dessas bases descoloniais do conhecimento, a Linguística Aplicada (LA) com uma visão interdisciplinar e transdisciplinar (KUMARAVADIVELU. B, 2006) propõe compreender o processo de aprendizagem enquanto continuo. Diariamente, aprender a desaprender. E um pouco do que nos diz Moita Lopes (2006, p. 86) sobre esta contemporaneidade que nos desafia a produzir conhecimentos e "colaborar para que se abram alternativas sociais com base nas e com as vozes dos que estão à margem". Junto a essas vozes destacam-se os remanescentes de quilombo não apenas no Brasil, mas em todo o mundo.

Os estudos sobre as relações étnico-raciais têm se intensificado a cada dia não apenas para garantir os direitos das comunidades excluídas pelo colonialismo - indígenas e quilombolas brasileiros -, mas também para disponibilizar alternativas teórico-práticas de caráter didático-pedagógico, voltadas para a consolidação de uma "cultura escolar cotidiana de reconhecimento e respeito as diversidades, as peculiaridades e ao repertorio cultural do povo negro, sem hierarquiza-los" (ROCHA, 2006, p. 24).

A dimensão étnico-racial e a prática pedagógica vêm a ser uma aliança rumo à interdisciplinaridade $e$ à construção de novos referenciais com o auxilio das Leis 10.639/2003 que institui o ensino de Historia e Cultura africana e afro-brasileira nas escolas, assim como a 11.645/2008 na aplicação do ensino de história e cultura indígena. Estas conquistas dos movimentos sociais e étnico-raciais envolvidos validaram a promoção de materiais voltados pra a descolonização linguística na educação. Como? A partir da edição de livros e outros materiais educativos que ilustram as vivencias dessas comunidades - afro e indígenas -, contribuindo de forma decisiva para o desenvolvimento da autoestima desses povos.

Em 2011, foram avaliadas algumas propostas para as bases pedagógicas para tratar da educação básica nas comunidades quilombolas brasileiras e diante dos pareceres com respeito às demandas dessa população. Logo foi sancionado em 2012 o documento que legitima a aplicação das diretrizes curriculares nacionais para a educação básica para a educação quilombola. Essas diretrizes deem ser aplicáveis nas diferentes modalidades de ensino, além de integra- 
rem a formação inicial e continuada dos professores que atuam em comunidades quilombolas rurais e urbanas. A compreensão da necessidade de se aplicar a educação quilombola em escolas rurais e urbanas deve ser levada a sério não apenas pelos quilombolas que vivenciam diretamente o processo ensino-aprendizagem com o currículo escolar voltado para suas ações mais específicas de cada comunidade, mas, também, à sociedade brasileira em ampla escala para respeitá-los e compartilhar vivências.

Antes da sanção da resolução sobre as diretrizes quilombolas, a SECAD já elaborava materiais de orientações e ações educativas relacionadas às questões étnico-raciais em que as especificidades dos costumes, tradições e elementos culturais quilombolas são mencionados como relevantes no processo de ensino-aprendizagem pós-moderno e pós-colonial. Para tal, a desobediência epistêmica deve ser praticada e a educação quilombola faz isto: leva para a sala de aula outras linguagens fora do padrão curricular de demais instituições escolares, logo, leva a sua sociedade novos letramentos a sua maneira. Saber a origem do conceito de quilombo (Kilombo ${ }^{2}$ - para Angola e seus reinos descendentes), sua natureza política, militar e econômica, suas diferenças e singularidades culturais já são uma revolução de signos linguísticos e simbólicos.

Segundo Angela Kleiman (2005), letramento é uma prática de linguagem coletiva e colaborativa (sociocultural) que usa a língua escrita e a oralidade como meios de aprendizado continuo e para todos. A leitura e uma das ferramentas e o professor, um dos agentes de letramento. A importância da leitura e o uso de diversos letramentos têm colaborado para a transformação positiva da sociedade que a pratica a exemplo, o uso

2 Outras formas de se chamar o agrupamento de negros fugidos da escravidão fora de África: Quilombo e Mocambo (Brasil); Cumbe (Venezuela); Palenque (Colômbia e Cuba). (MOURA, Clóvis; 1993). do Hip-Hop como um agente de letramento e visa levar educação, senso crítico e politização à comunidade negra usando os elementos -rap, Dj, grafite, dança como ferramentas (SOUZA, 2011). Conforme Souza,

\begin{abstract}
A singularidade esta nas microrresistências cotidianas ressignificadas na linguagem, na fala, nos gestos, nas roupas [...]. Essa perspectiva de Letramento, que acothe e legitima os letramentos no movimento hip-hop [...], pelo fato de fazerem sentido e de serem significativos para os sujeitos de conhecimentos e de direito [...] (SOUZA, 2011, p. 37).
\end{abstract}

As comunidades quilombolas têm suas práticas sociais e com elas exercem a cidadania e reinventam suas tradições. Essa educação diferenciada, que respeita as diferenças e a cultura local, também, forma seus estudantes criticamente sobre as questões de territorialidade, a geopolítica de sua população (econômica e politica), a história dos quilombolas e seus modos de resistências. Junto a estes pontos das diretrizes, a compreensão sobre o letramento renasce a esperança da LA por uma educação "intercultural, interlinguística e interdisciplinar” (MOITA LOPES, 2006, p.139).

Enquanto comunidades negras, os quilombos têm representado no Brasil um arsenal de conhecimento econômico e politico que merecem reverência e promoção de seus letramentos na formação educativa brasileira (ver materiais paradidáticos elaborados pela SECAD com o auxílio de escolas quilombolas e sua prática pedagógica nas comunidades situadas em Minas Gerais e Goiás) ${ }^{3}$. A memória, a história, a identidade negra e seus traços culturais mantêm o aquilombamento vivo e dão suporte a práxis escolar.

3 Estórias Quilombolas. Glória Moura (Org.). Brasília: Ministério da Educação, Secretaria da Educação Continuada, Alfabetização e Diversidade, 2010. 100 p. 


\section{QUADRINHOS E SEUS QUILOMBOS}

Analisaram-se duas revistas em quadrinhos de autores diferentes, contudo, todos publicados no Brasil pela SECAD e voltados ao público infanto-juvenil. Far-se-á observações quanto ao teor das histórias, as imagens ou ilustrações de seus personagens, além do formato da edição do material.

O gibi Quilombos: Espaço de Resistência de crianças, jovens, mulheres e homens negros foi criado pela Rede de Desenvolvimento Humano (REDEH), editado pela SECAD, apresenta histórias relacionadas à população quilombola existente no território brasileiro. Toda a revista envolve narrativas de comunidades quilombolas cujos pesquisadores são estudantes de uma escola quilombola local que fazem um tour nas demais comunidades a fim de coletar as narrativas fundadoras locais. A primeira história conta relata sobre o Quilombo Campinho da Independência localizado no sul do estado do Rio de Janeiro. Estão envolvidos enquanto protagonistas crianças da comunidade mencionada. A professora e os demais personagens são todos negros e não há marcas de estereotipagem nem marcas preconceituosas. A segunda história é sobre o Quilombo de Santana. Há a presença de uma anciã para contar as especificidades do local. Aponta a relevância de projetos de ONGs e do governo federal pra manter a história do local viva e presente.

Os demais quadrinhos vão perpassar pelos quilombos São José da Serra, Caveiras/Botafogo, Quilombo da Rasa e, por fim, Quilombo da Fazenda Machadinha onde são rememoradas comidas típicas da localidade, a cultura do Jongo, o Fado além da extinção do Cantador de Reis. Toda a pesquisa resulta em uma revistinha em quadrinhos (logo uma metalinguagem da própria obra), com as principais histórias coletadas. $\mathrm{Na}$ contracapa é apresentado um mapa do estado carioca com a localização dos territórios quilombolas locais.

Minas de Quilombos faz parte de uma coletânea de materiais paradidáticos editados pela SECAD para serem aplicados em escolas quilombolas que trabaIham com a educação básica. Também criado pela REDEH - ambos de 2010 -, vem a narrar histórias dos quilombos de Minas Gerais, cujo ambiente de contação é uma sala de aula, porém, com a presença de personagens de outros grupos étnico-raciais - negros e brancos. Traz como atrativo no início da história um relato sobre a revistinha em quadrinhos Quilombos: Espaço de Resistência de crianças, jovens, mulheres e homens negros, citada acima.

A partir dessa provocação, a professora da escola quilombola vai instigando seus alunos a procurarem saber mais sobre a comunidade em que vivem e sua relevância histórica. Traz à baila aspectos linguísticos e culturais partilhados pelos africanos que ali foram escravizados. Novamente há a menção de anciãos para auxiliarem no domínio da história local. Comunidades ilustradas: Quilombo do Baú, Comunidade do Espinho, Quilombo do Açude, Mato do Tição, Quilombo do Sapé, Pinhões e Comunidade Afro-descendente de Quilombo Mangueira. Assim como o quadrinho Quilombos, este, também, se torna uma revistinha em quadrinhos e ao fim possui um mapa do estado de Minas Gerais com a referência dos quilombos citados. 


\section{CONSIDERAÇ̃̃ES FINAIS}

As revistinhas em quadrinhos apresentadas contêm aspectos diferenciados quanto ao propósito de sua edição: algumas buscam um direcionamento à prática pedagógica incitando a pesquisa sobre demais comunidades quilombolas, a história e cultura

\section{REFERENCIAS}

KLEIMAN, Angela B. Preciso "ensinar" o letramento? Não basta ensina a ler e a escrever? Ministério da Educação, 2005.

KUMARAVADIVELU. B. A linguística aplicada na era da globalização. In: Por uma Linguística Aplicada INdisciplinar. Branca Fabricio [et al]; Luiz Moita Lopes (org.). São Paulo: Parábola Editorial, 2006, p. 129-148.

MIGNOLO, Walter. Desobediência epistêmica: a opção descolonial e o significado de identidade em politica. 2008, p. 287-324.

MINISTERIO DA EDUCACAO/SECRETARIA DA EDUCACAO CONTINUADA, ALFABETIZACAO E DIVERSIDADE. Orientações e Ações para a Educação das relações étnico-raciais. Brasília: SECAD, 2006, p.137-162.

MOITA LOPES, Luiz Paulo da. Linguística Aplicada e vida contemporânea: problematização dos construtos que tem orientado a pesquisa. In: Por uma Linguística Aplicada INdisciplinar. Branca Fabricio [et al]; Luiz Moita Lopes (org.). São Paulo: Parábola Editorial, 2006, p. 85-107. das mesmas além da manutenção da ideia de respeito às tradições e aos costumes afro-descendentes no Brasil. Pode-se afirmar que se trata de um recurso de leitura muito bem orientado e cabível em diferentes níveis da educação básica infanto-juvenil (séries iniciais, Fundamental I e II), com uma linguagem acessível e ilustrações éticas e respeitosas.

MOURA, Clóvis. Quilombos: Resistência ao escravismo. 3. ed. Série Princípios. São Paulo: Ática, 1993.

NASCIMENTO, Beatriz. O conceito de quilombo e a resistência afro-brasileira. In: Cultura em movimento: matrizes e ativismo negro no Brasil. Elisa Larkin Nascimento (Org.) São Paulo: Selo Negro, 2008 (Sankofa: Matrizes africanas da cultura brasileira; 2), p. 71-91.

ROCHA, Rosa Margarida de Carvalho. Educação das relações étnico-raciais: pensando referências para a organização da prática pedagógica. Belo Horizonte: Mazza Edições, 2007.

SOUZA, Ana Lúcia silva. Letramentos de Reexistência: poesia, grafite, música, dança: HIP-HOP. São Paulo: parábola Editorial, 2011. 
$\cdot 156 \cdot$

Recebido em: 15 de Julho de 2013

Avaliado em: 20 de Novembro de 2013

Aceito em: 19 de Dezembro de 2013

1 Mestranda em Critica Cultural (UNEB- Campus II). 